\title{
Updates in Cerebral Venous Thrombosis
}

\author{
Arshia Alimohammadi ${ }^{1,3} \cdot$ Diana J. Kim ${ }^{1,2} \cdot$ Thalia S. Field $^{1,2,3}$ \\ Accepted: 26 September 2021 / Published online: 13 January 2022 \\ (c) The Author(s), under exclusive licence to Springer Science+Business Media, LLC, part of Springer Nature 2022
}

\begin{abstract}
Purpose of Review Cerebral venous thrombosis (CVT) is a rare cause of stroke that most commonly affects younger women. Here, we review new literature relevant to the management and prognosis of individuals with CVT and ongoing areas of uncertainty.

Recent Findings Direct-acting oral anticoagulants (DOACs) are being increasingly integrated into routine care but are not yet recommended by guidelines. Recent randomized clinical trials and available case series offer reassuring safety data. Routine use of endovascular therapy is not associated with improved outcomes. The relationship between recanalization and prognosis is uncertain.

Summary The evidence base for management of CVT continues to improve. Ongoing areas of uncertainty include duration of therapy and whether certain subgroups of patients may benefit from neurointervention or personalized approaches to antithrombotic strategy. The state of knowledge will continue to benefit from large collaborative international efforts, and integration of patient partnerships to identify research priorities.
\end{abstract}

Keywords Cerebral venous thrombosis $\cdot$ Anticoagulation $\cdot$ DOAC $\cdot$ Recanalization $\cdot$ Prognosis $\cdot$ Endovascular therapy

\section{Introduction}

Cerebral venous thrombosis (CVT) accounts for approximately $0.5-1 \%$ of all strokes [1]. In contrast to other venous thromboses of "unusual sites," which altogether comprise approximately $10 \%$ of all venous thromboembolism, CVT predominantly affects young patients and women of reproductive age [2]. Approximately $80 \%$ of

This article is part of the Topical Collection on Stroke

Thalia S. Field

thalia.field@ubc.ca

Arshia Alimohammadi

aarshia@alumni.ubc.ca

Diana J. Kim

dianajykim@gmail.com

1 Faculty of Medicine, University of British Columbia, Vancouver, Canada

2 Division of Neurology, University of British Columbia, S169-2211 Wesbrook Mall, Vancouver, BC V6T 2B5, Canada

3 Vancouver Stroke Program, Vancouver General Hospital, Vancouver, Canada cases affect individuals under the age of 50 , and $75 \%$ of cases affect women [1]. Although the majority of survivors will achieve functional independence, $10-15 \%$ will have a more serious outcome resulting in death or dependence [3, 4]. Even higher-functioning survivors experience underrecognized disability from cognitive impairment, mood, fatigue and pain, which significantly impact quality of life $[5,6]$.

Due to the rarity of CVT, large randomized trials are not available to guide management. Standard-of-care treatments are consensus-based, derived mainly from observational studies or underpowered clinical trials [7, 8]. In the last few years, however, several new studies have advanced our understanding of treatment strategies and complications of CVT. Multiple ongoing trials will further clarify areas of lasting clinical equipoise in the near future.

There are a number of excellent contemporary reviews summarizing the current landscape of knowledge with respect to epidemiology, risk factors, clinical manifestations, diagnosis, prognosis and management of CVT $[9 \bullet, 10,11]$. Here, we provide a focused update of new data that will help to inform contemporary management and identify areas of ongoing uncertainty. 


\section{Epidemiology}

While the incidence of more common forms of venous thromboembolic disease (VTE), such as deep venous thrombosis of the leg and pulmonary embolism (DVT/PE), is about 1-2 per 1000 person-years [12], previous estimates of incident CVT are approximately 1 per 100,000 personyears $[13,14]$. Likely due in part to improved ascertainment with increased use of routine vascular neuroimaging with $\mathrm{CT}$ angiography/venography, recent reports of incidence have been somewhat higher. Recent Australian and Norwegian studies using administrative data estimated rates of 1.6 and 1.75/100,000/year, respectively [14, 15]. A new Finnish study found an overall rate of $1.3 / 100,000 /$ year, with incidence increasing annually by 5\% between 2005 and 2014 [16]. Another new study using American inpatient data from New York and Florida found an incidence of 1.4-2/100,000 person-years between 2006 and 2016, also finding increasing annual incidence for both men and women [17•]. Similar to studies of DVT/PE, rates were higher in those with Black race-ethnicity than in those of Caucasian or Asian descent. To what degree these disparities reflect genetic as opposed to environmental factors in the context of social determinants of health is not known [17•]. A recent genome-wide association study in Europeans identified the first chromosomal region associated with genetic susceptibility to CVT in the $9 q 34.2$ locus. Single-nucleotide polymorphisms in this region were in strong linkage disequilibrium with $\mathrm{ABO}$ blood type gene coding. Risk of CVT with blood group Types A, AB, or B was 2.85 (95\% CI 2.32-3.52) times of that with type $\mathrm{O}[18 \bullet \bullet]$.

In contrast to DVT/PE, which becomes more common with age and affects roughly equal numbers of men and women [19], CVT more often affects younger women. Rates of CVT in women of childbearing age are approximately $3 / 100,000 / y e a r$ [13]. This is likely in part due to its association with pregnancy and the puerperium as well as hormonal contraception. CVT accounts for approximately one-third of pregnancy-associated stroke at an incidence of 9/100,000 pregnancies [20]. Oral contraceptives are a contributing factor in up to $70 \%$ of cases [21]. One case-control study identified a synergistic effect of obesity on the risk of CVT associated with oral contraception. However, $16 \%$ of the body mass index data was missing and substituted by interpolation, and further studies are needed to confirm this finding [22].

Other non-genetic and genetic risk factors for CVT have been recently summarized in a meta-analysis incorporating 20 non-genetic and 33 genetic studies [23•]. Significant acquired and genetic factors are summarized in Table 1.

During the past 18 months, there have been numerous reports of CVT associated with SARS-CoV-2 infection,
Table 1 Risk factors for CVT in adults [23•]

\begin{tabular}{ll}
\hline Non-genetic & Genetic \\
\hline Provoking & Factor V Leiden \\
Anaemia & MTHFR (C677T) \\
APLAS and other autoimmune disease & Prothrombin gene mutation \\
Malignancy & Protein C deficiency \\
Medications: oral contraceptive, & Protein S deficiency \\
$\quad$ corticosteroids, L-aspariginase & \\
Obesity & \\
Pregnancy/puerperium & \\
Trauma & \\
Surgery & \\
Infection & \\
Alcohol & \\
\hline
\end{tabular}

both as a late complication of severe infection and as an isolated presenting symptom [24•, 25]. In contrast to estimated rates of COVID-19-associated deep vein thrombosis and pulmonary embolism, which appear to be upwards of $15-20 \%$ in hospitalized patients [26, 27], reported rates of CVT to date appear to be low overall. Estimated frequency in data from 34,000 hospitalized patients with COVID-19 in a recent meta-analysis of 28 reports was $0.08 \%$ (95\% CI 0.01-0.05), with CVT accounting for $4 \%$ of cerebrovascular disorders in individuals with COVID-19 [24•]. The literature on COVID-19-associated CVT is constantly evolving, and its prevalence may be underestimated in the absence of routine vascular neuroimaging.

In March 2021, reports emerged regarding multiple cases across Europe of thromboses at unusual sites, predominantly CVT, with thrombocytopenia, very high d-dimer levels and reduced fibrinogen [28, 29]. Cases were reported following vaccination with the ChAdOx $1 \mathrm{nCoV}-19$, generally within 4-28 days of the first dose and with a predominance towards younger adults and women [30-32]. Cases occurring with CVT as part of the presentation reported much higher case mortality rates (in excess of 30\%) than in historical series of CVT ( 5-10\%) [33]. Other reports followed from other countries with similar cases after ChAdOx1 and Ad26. COV2.S, another adenovirus vector vaccine against SARSCoV-2. An international collaborative effort identified a mechanism akin to spontaneous heparin-induced thrombocytopenia (HIT) as the pathophysiological mechanism [34]. High-titre serum antibodies to platelet factor 4 (PF4), known to be associated with HIT and not typically associated with CVT, were identified in association with the reaction [35-37, $38 \bullet \bullet$. The syndrome, termed both VITT (vaccine-induced thrombocytopenia) or TTS (thrombosis with thrombocytopenia syndrome), led to changes in vaccination strategies in multiple countries where use of the adenovirus vector SARS-Cov-2 vaccinations was subsequently limited to older 
age groups or stopped entirely. Estimated rates of VITT/TTS varied, ranging from $1 / 25,000$ to under $1 / 1,000,000$ [28, 31, 39]. Recommended treatment approaches included avoiding heparins and avoiding platelet transfusions where possible, and using intravenous immunoglobulin with or without steroids or, in refractory cases, considering plasma exchange or monoclonal antibodies $[40,41 \bullet \bullet]$.

\section{Clinical Presentation and Diagnosis}

Recent reviews have described approaches to the clinical evaluation and diagnosis of CVT [9•, 10, 11, 42].

Initial clinical presentation can reflect symptoms accrued from raised intracranial pressure, location of thrombosis and thrombus burden. Common presentations include headache, seizures, focal symptoms and depressed level of consciousness. Most patients present subacutely within 48 $\mathrm{h}$ to 2 weeks of symptom onset; one-third to one half will present more acutely with stroke-like symptoms or thunderclap headache $[43,44]$. Presenting symptoms in the two largest prospective series of CVT, the International Study of Cerebral Venous Thrombosis (ISCVT) [43] and the Turkish VENOST study [44], are summarized in Table 2.

A substudy of the ISCVT found that elderly patients were more likely to present with depressed level of consciousness and less likely to have isolated symptoms of intracranial hypertension [45]. One recent prospective international study of 1281 individuals found a 34\% rate of acute symptomatic seizures, $6 \%$ of whom had status epilepticus. Neuroimaging findings associated with acute seizures included intracerebral haemorrhage, non-haemorrhagic lesions, cortical vein or sagittal sinus thrombosis and subarachnoid haemorrhage [46].

Table 2 Presenting findings of cerebral venous thrombosis

\begin{tabular}{lll}
\hline & ISCVT (2004) & VENOST (2017) \\
\hline $\mathrm{N}$ & 624 & 1144 \\
Age & 39 (mean) & $18-36$ y (47\%) \\
& 37 (median), range & $37-50(33 \%)$ \\
\% Female & $16-86$ & $51+(20 \%)$ \\
Headache & 75 & 68 \\
Visual loss & $89 \%$ & $87 \%$ \\
Cranial neuropathy/ & $13 \%$ (diplopia only) & $11 \%$ \\
$\quad$ diplopia & & \\
Depressed level of & $22 \%$ & $18 \%$ \\
consciousness/ & & \\
encephalopathy & & $24 \%$ \\
Seizure & $40 \%$ & $18 \%$ \\
Focal deficits & Motor 40\% & \\
& Sensory 5\% & \\
& Other 3\% &
\end{tabular}

\section{Treatment Strategy}

The mainstay of acute treatment for CVT is anticoagulation. Goals of therapy predominantly focus on preventing thrombus propagation, restoring anterograde drainage, salvaging brain tissue from permanent damage and preventing recurrent thromboembolism [7]. Identifying and treating any underlying hypercoagulable state is paramount for long-term management. Supportive measures and management of complications include hydration, headache and seizure management and treatment of increased intracranial pressure.

\section{Acute Treatment}

\section{Anticoagulation}

Anticoagulation remains the first-line treatment of choice of CVT in the acute setting, even when there is concurrent intracranial haemorrhage (ICH). Although series estimate a $30-45 \%$ prevalence of intracranial bleeding at presentation [47-49], none to date have characterized haemorrhage type [50].

Existing reports suggest that a minority of patients will have new or worsening haemorrhage on follow-up scans, more commonly with those who have baseline ICH (9-21\%) as opposed to those without (3-10\%) [47, 49].

Both American and European guidelines recommend initiation of parenteral anticoagulation with unfractionated or low molecular-weight heparin prior to transitioning to oral anticoagulants [7,8]. European guidelines provide a weak recommendation for low-molecular weight heparin (LMWH) over unfractionated heparin (UFH) based on a meta-analysis suggesting a non-significant trend towards improved functional outcomes and mortality with the former without a difference in rates of bleeding $[8,51]$.

\section{Endovascular Therapy and Hemicraniectomy}

Both American and European guidelines recommend use of endovascular therapy (EVT) only for individuals who continue to worsen clinically despite use of first-line anticoagulation [7, 8]. The TO-ACT trial examined use of neurointervention (with approach as per local standards) versus conservative management in patients with severe CVT (defined as presence of deep venous involvement, intracranial haemorrhage, mental status changes or Glasgow coma score $(\mathrm{GCS})<9)$. The trial was terminated early for futility after 67 participants of a target of 164 were randomized and found no difference in the rates of the primary endpoint of a modified Rankin Score (mRS) of 0-1 at 12 months (67\% vs. $68 \%$; RR $0.99,95 \%$ CI $0.71-1.38$ ). Three of 33 participants in the EVT group experienced periprocedural sinus 
perforation [52••]. Use of EVT remains a case-by-case decision in current practice. Future work may help to identify individuals that may benefit from EVT as well as optimal technical approaches.

Decompressive hemicraniectomy similarly remains a caseby-case measure for those at risk of malignant mass effect from oedema and/or intracranial haemorrhage. A previous case series and systematic review of 69 individuals undergoing decompressive hemicraniectomy for CVT found overall rates of death or dependence of $40 \%$ at 12 months [53]. However, final results of the prospective DECOMPRESS-2 Trial, which were presented at the 2021 European Stroke Organization Conference but are not yet published, found higher rates of unfavourable outcomes, with $65 \%$ of 118 individuals achieving a mRS of 3-6 at 12 months. Over half of participants (58\%) characterized as comatose prior to surgery, 23\% with unilateral absent pupillary responses and $8 \%$ with bilaterally absent pupillary responses [54]. The optimal timing of restarting anticoagulation after hemicraniectomy is not established. A recent case series and review including 243 patients from 15 studies identified multiple approaches, though overall quality of the literature was low and reporting of early post-operative re-bleeding was heterogeneous [55]. The post-operative approach at our centre is to initiate nextday prophylactic dose of low molecular-weight heparin with daily escalation guided by repeat neuroimaging to reassess for intracranial bleeding.

\section{Post-acute Treatment}

\section{Use of DOACs in CVT}

Following acute treatment, most patients transition from parenteral therapy to oral anticoagulation. Current guidelines recommend using oral Vitamin $\mathrm{K}$ antagonists (VKA) with European guidelines recommending against routine use of direct-acting oral anticoagulants (DOACs) in CVT, particularly as initial therapy [7,8]. Yet despite lacking formal endorsement in current guidelines, DOACs are being increasingly used in clinical practice as treatment for CVT, particularly following the acute phase of treatment $[56,57 \bullet]$. DOACs have demonstrable safety and efficacy for treatment of DVT/PE [58-61]; for instance, there is a 50\% relative risk reduction in rate of intracranial bleeding in comparison to both VKA and LMWH [62].

To date, two clinical trials examining use of DOACs for treatment of CVT have shown reassuring safety data. The exploratory RESPECT-CVT Trial randomized (1:1) 120 adults ages 18-80 with CVT to receive VKA (target INR 2-3) or dabigatran $150 \mathrm{mg}$ twice daily between 5 and 15 days of diagnosis, following initial therapy with parental anticoagulation. Individuals with CVT associated with trauma, infection or malignancy were excluded. There was no difference between groups in the primary safety outcome of major bleeding or any VTE recurrence at 6 months, with one gastrointestinal haemorrhage in the dabigatran group and two intracranial haemorrhages in the VKA group. Majority of participants (91\%) had a mRS of 0-1 at 6 months; furthermore, $60 \%$ in the dabigatran group and $67 \%$ in the warfarin group achieved partial or complete recanalization [63••]. The EINSTEIN-Jr trial randomized (2:1) 520 children with symptomatic VTE to a bodyweight-adjusted 20-mg-equivalent dose of rivaroxaban versus VKA or ongoing parental treatment following 5-9 days of parenteral anticoagulation. The primary efficacy outcome was recurrent VTE at 3 months, and the primary safety outcome was major or clinically relevant non-major bleeding. In the substudy examining the 114 children enrolled with neuroimagingconfirmed CVT, none of the 73 receiving rivaroxaban and 1 in the standard therapy group experienced recurrent VTE. There were no major bleeding events in the rivaroxaban group; five children in the group had clinically relevant nonmajor bleeding events. In the standard therapy group, there was one major bleeding event (subdural haemorrhage), and no relevant non-major bleeding events. Partial or complete recanalization occurred in $78 \%$ in the rivaroxaban group and $74 \%$ in the standard therapy group [64••].

Whether DOACs may be an acceptable choice for initial therapy in place of parenteral anticoagulation in selected CVT patients is not established. Further studies are additionally needed to clarify whether VTE initiation dosing or atrial fibrillation dosing is more optimal. The reported experiences in case series are variable [57•]. The ongoing SECRET trial, which is randomizing individuals with CVT 1:1 to rivaroxaban $20 \mathrm{mg}$ daily versus standard therapy (VKA or parenteral anticoagulation) within 14 days of diagnosis, permits use of $20 \mathrm{mg}$ rivaroxaban as initial therapy (clinicaltrials.gov NCT03178864) [65].

DOACs will not be suitable in some patients, including those who are pregnant, breastfeeding (11-59\% of cases depending on cohort) [21] or those with antiphospholipid antibody syndrome (APLAS), especially high-risk patients with triple-antibody-positive disease. The TRAPS trial randomized individuals with high-risk APLAS (i.e. triple antibody-positive with prior venous or arterial thromboembolism) to rivaroxaban versus VKA and was terminated early due to an excess of recurrent arterial events in the rivaroxaban group [66•]. This has raised concerns about the safety of using DOACs in APLAS [67], though other DOAC trials are ongoing in lower-risk patients [68]. The rate of APLASassociated CVT is uncertain. A previous systematic review found a $6-17 \%$ prevalence of antiphospholipid antibodies, though rates of those meeting true diagnostic criteria for APLAS were not consistently reported [21]. Prevalence of incidental antiphospholipid antibodies in the general population is approximately $2-4 \%$ [69]. 


\section{Duration of Therapy and Recanalization}

American and European guidelines for duration of anticoagulation mirror recommendations for other types of VTE: 3-6 months of anticoagulation for provoked CVT, 6-12 months for unprovoked CVT and indefinite anticoagulation for severe thrombophilias and recurrent VTE [7, 8]. Previous physician surveys indicate that practice is variable, though most tend towards 6 months of treatment for uncomplicated cases $[70,71]$. The EX-COA study, which is examining efficacy and safety (recurrent VTE, bleeding and death) of 3-6 months versus 12 months of VKA anticoagulation in CVT, may help to clarify the optimal duration of antithrombotic over the shorter term [72].

The role and timing of repeat neuroimaging in assessing recanalization and thrombus burden is unclear. The recent prospective PRIORITy-CVT study, which imaged 68 individuals with CVT with standardized MRI/MR venography at $48 \mathrm{~h}, 8$ days and 90 days following initiation of anticoagulation, found that $74 \%$ had partial $(68 \%)$ or full $(6 \%)$ recanalization within 8 days of initiating therapy, and $95 \%$ had partial $(41 \%)$ or complete $(54 \%)$ recanalization by 90 days [73••]. While early recanalization was associated with regression of non-haemorrhagic lesions, there was no association between recanalization status and new or enlarged haemorrhagic lesions, or recanalization status and favourable functional outcome.

There is inconsistent evidence for whether recanalization is associated with functional outcome, and what the directionality and time-dependence of that relationship may be. Neither PRIORITy-CVT [73••] nor a prospective substudy of RESPECT-CVT found an association between recanalization and functional outcome [74]; however, both were likely unpowered for this outcome. A recent meta-analysis examining the association between recanalization and prognosis found that complete or partial recanalization was associated with an increased odds of functional independence (mRS 0-1) [75]. However, all 19 studies included were appraised as having moderate or low methodological quality, and definitions of recanalization and timing of clinical and imaging assessments were variable between studies. The significance and prognostic implications of recanalization status are yet to be fully determined.

In PRIORITy-CVT, residual headache was not associated with recanalization status. A large prospective series of 325 individuals with CVT from China described an association between severe headache (residual headache requiring bed rest or readmission to hospital 1 month or less prior to follow-up assessment, with a median time to follow-up of 13 months) and absence of recanalization, though follow-up neuroimaging was not systematic [76].

While extended antithrombotic therapy is of benefit in reducing risk of recurrent VTE after DVT/PE, it is not known whether this should be extrapolated to the CVT population, who are younger and likelier to have had a provoked event. In all comers, the risk of recurrent VTE after CVT averages approximately $2-4 \%$ per year [77•], with risk increasing somewhat linearly over time. In those without high-risk thrombophilias, risk of recurrence appears to be lower. One prospective cohort of 203 patients without highrisk thrombophilia followed over a median of 36 months found a recurrence risk of 1.6/100 person-years [78•]. Risk was higher in men, and in those who were heterozygotes for Factor V Leiden or prothrombin gene mutation. Those with unprovoked events have also been identified as higher risk for recurrence in other series [77•]. Prophylactic anticoagulation is indicated in women with a history of CVT in the context of oral contraception or pregnancy [7]. Whether some individuals with a history of CVT would benefit from targeted prophylaxis in other higher-risk scenarios is not known.

\section{Prognosis}

Large observational series of CVT have reported an approximate $10-15 \%$ rate of death and dependence (mRS 3-6) [3, 4]. Previous risk factors identified for poorer prognosis include older age, male sex, presence of intracranial haemorrhage on presentation, and depressed level of consciousness or coma [3,4]. Although most CVT survivors will retain functional independence, retrospective surveys of CVT survivors report high rates of sequelae impacting quality of life, including pain, mood, fatigue and cognitive residua, even several years following their events. Retrospective series in CVT survivors have found that over half do not return to work, or have difficulty after returning to work, following their event [5, 6].

A recent prospective study describing late seizures in CVT, defined as seizures occurring later than 1 week after diagnosis, found that $11 \%$ of 1127 experienced at least one event over a median follow-up of 2 years, with a median time to seizure of 5 months. Predictors included status epilepticus in the acute phase of presentation, decompressive hemicraniectomy and intracerebral haemorrhage. Of those with late seizures, although $94 \%$ were started on antiepileptic therapy, $70 \%$ experienced at least one recurrent event [79••].

Dural arteriovenous fistula is a known complication of cerebral venous thrombosis in addition to an identified precipitant, but the prevalence is not well characterized, and there are no recommendations with respect to follow-up for this indication. A recent prospective substudy of the 120 participants from the RESPECT-CVT trial found no dural AV fistulas at 6-month follow-up contrast-enhanced MR angiography [80]. Follow-up, however, was brief, and 95\% confidence interval estimates for this cohort would be 
0-2.5\% [81]. Other smaller series using variable approaches identification of dAVF and with variable timing after CVT have reported rates of $0.9-13 \%$ [43, 82, 83].

\section{Conclusions}

Several recent and ongoing studies are contributing to a fuller state of understanding with respect to treatment and prognosis of this rare cause of stroke. Further progress will be in the context of ongoing international collaboration, which will help to generate sufficiently large cohorts to identify subgroups that may benefit from variations in acute and longer-term treatment strategies. A fuller picture of prognosis after CVT beyond $\mathrm{mRS}$-focused outcomes is emerging, and ongoing collaboration with CVT survivors in identifying and characterizing patient-centred outcomes will help to better support survivors of this rare cause of stroke.

\section{Compliance with Ethical Standards}

Conflict of Interest Dr. Field is PI for the SECRET (Study of rivaroxaban for ceREbral venous Thrombosis) trial and receives in-kind study medication from Bayer Canada for the study. She is supported by the Vancouver Coastal Health Research Institute, the Michael Smith Foundation for Health Research, the Heart and Stroke Foundation of Canada. The other authors declare that they have no conflict of interest.

Human and Animal Rights and Informed Consent This article does not contain any studies with human or animal subjects performed by any of the authors.

\section{References}

Papers of particular interest, published recently, have been highlighted as:

- Of importance

$\bullet$ Of major importance

1. Bousser M-G, Ferro JM. Cerebral venous thrombosis: an update. Lancet Neurol. 2007;6:162-70.

2. Shatzel JJ, O'Donnell M, Olson SR, Kearney MR, Daughety MM, Hum J, et al. Venous thrombosis in unusual sites: a practical review for the hematologist. Eur J Haematol. 2019;102:53-62.

3. Canhão P, Ferro JM, Lindgren AG, Bousser M-G, Stam J, Barinagarrementeria $\mathrm{F}$, et al. Causes and predictors of death in cerebral venous thrombosis. Stroke. 2005;36:1720-5.

4. Coutinho JM, Ferro JM, Canhão P, Barinagarrementeria F, Cantú $\mathrm{C}$, Bousser M-G, et al. Cerebral venous and sinus thrombosis in women. Stroke. 2009;40:2356-61.

5. Koopman K, Uyttenboogaart M, Vroomen PC, van der Meer J, De Keyser J, Luijckx G-J. Long-term sequelae after cerebral venous thrombosis in functionally independent patients. J Stroke Cerebrovasc Dis. 2009;18:198-202.
6. Hiltunen S, Putaala J, Haapaniemi E, Tatlisumak T. Long-term outcome after cerebral venous thrombosis: analysis of functional and vocational outcome, residual symptoms, and adverse events in 161 patients. J Neurol. 2016;263:477-84.

7. Saposnik G, Barinagarrementeria F, Brown RD Jr, Bushnell CD, Cucchiara B, Cushman M, et al. Diagnosis and management of cerebral venous thrombosis: a statement for healthcare professionals from the American Heart Association/American Stroke Association. Stroke. 2011;42:1158-92.

8. Ferro JM, Bousser M-G, Canhão P, Coutinho JM, Crassard I, Dentali F, et al. European Stroke Organization guideline for the diagnosis and treatment of cerebral venous thrombosis endorsed by the European Academy of Neurology. Eur J Neurol. 2017;24:1203-13.

9. Ulivi L, Squitieri M, Cohen H, Cowley P, Werring DJ. Cerebral venous thrombosis: a practical guide. Pract Neurol. 2020;20:35667. Comprehensive review focused on current standards for clinical management.

10. Durmuş B, Yperzeele L, Zuurbier SM. Cerebral venous thrombosis in women of childbearing age: diagnosis, treatment, and prophylaxis during a future pregnancy. Ther Adv Neurol Disord. 2020;13:1756286420945169.

11. de Sousa DA. Cerebral venous thrombosis: what's new? Hamostaseologie. 2021;41:025-30.

12. Beckman MG, Hooper WC, Critchley SE, Ortel TL. Venous thromboembolism: a public health concern. Am J Prev Med. 2010;38:S495-501.

13. Coutinho JM, Zuurbier SM, Aramideh M, Stam J. The incidence of cerebral venous thrombosis: a cross-sectional study. Stroke. 2012;43:3375-7.

14. Devasagayam S, Wyatt B, Leyden J, Kleinig T. Cerebral venous sinus thrombosis incidence is higher than previously thought: a retrospective population-based study. Stroke. 2016;47:2180-2.

15. Kristoffersen ES, Harper CE, Vetvik KG, Zarnovicky S, Hansen JM, Faiz KW. Incidence and mortality of cerebral venous thrombosis in a Norwegian population. Stroke. 2020;51:3023-9.

16. Ruuskanen JO, Kytö V, Posti JP, Rautava P, Sipilä JOT. Cerebral venous thrombosis: Finnish nationwide trends. Stroke. 2021;52:335-8.

17. Otite FO, Patel S, Sharma R, Khandwala P, Desai D, Latorre $\mathrm{JG}$, et al. Trends in incidence and epidemiologic characteristics of cerebral venous thrombosis in the United States. Neurology. 2020;95:e2200-13. Describes US trends in increasing incidence of CVT by sex and race-ethnicity.

18.• Ken-Dror G, Cotlarciuc I, Martinelli I, Grandone E, Hiltunen S, Lindgren E, et al. Genome-wide association study identifies first locus associated with susceptibility to cerebral venous thrombosis. Ann Neurol. 2021. https://doi.org/10.1002/ana.26205. GWAS study in individuals with CVT.

19. White RH. The epidemiology of venous thromboembolism. Circulation. 2003;107:I4-8.

20. Swartz RH, Cayley ML, Foley N, Ladhani NNN, Leffert L, Bushnell $\mathrm{C}$, et al. The incidence of pregnancy-related stroke: a systematic review and meta-analysis. Int J Stroke. 2017;12:687-97.

21. Silvis SM, Middeldorp S, Zuurbier SM, Cannegieter SC, Coutinho JM. Risk factors for cerebral venous thrombosis. Semin Thromb Hemost. 2016;42:622-31.

22. Zuurbier SM, Arnold M, Middeldorp S, Broeg-Morvay A, Silvis SM, Heldner MR, et al. Risk of cerebral venous thrombosis in obese women. JAMA Neurol. 2016;73:579-84.

23. Green M, Styles T, Russell T, Sada C, Jallow E, Stewart J, et al. Non-genetic and genetic risk factors for adult cerebral venous thrombosis. Thromb Res. 2018;169:15-22. Comprehensive meta-analysis of case-control studies examining risk factors for CVT. 
24. Baldini T, Asioli GM, Romoli M, Carvalho Dias M, Schulte EC, Hauer L, et al. Cerebral venous thrombosis and severe acute respiratory syndrome coronavirus-2 infection: a systematic review and meta-analysis. Eur J Neurol. 2021. https://doi.org/10.1111/ ene.14727. Most current meta-analysis examining CVT in SARS-CoV-2 infection.

25. Abdalkader M, Shaikh SP, Siegler JE, Cervantes-Arslanian AM, Tiu C, Radu RA, et al. Cerebral venous sinus thrombosis in COVID-19 patients: a multicenter study and review of literature. J Stroke Cerebrovasc Dis. 2021;105733. https://doi.org/10. 1016/j.jstrokecerebrovasdis.2021.105733.

26. Malas MB, Naazie IN, Elsayed N, Mathlouthi A, Marmor R, Clary B. Thromboembolism risk of COVID-19 is high and associated with a higher risk of mortality: a systematic review and meta-analysis. EClinicalMedicine. 2020;29:100639.

27. Tan BK, Mainbourg S, Friggeri A, Bertoletti L, Douplat M, Dargaud Y, et al. Arterial and venous thromboembolism in COVID-19: a study-level meta-analysis. Thorax. 2021. https:// doi.org/10.1136/thoraxjnl-2020-215383.

28. Krzywicka K, Heldner MR, Sánchez van Kammen M, van Haaps $\mathrm{T}$, Hiltunen S, Silvis SM, et al. Post-SARS-CoV-2-vaccination cerebral venous sinus thrombosis: an analysis of cases notified to the European Medicines Agency. Eur J Neurol. 2021. https:// doi.org/10.1111/ene.15029.

29. Pavord S, Scully M, Hunt BJ, Lester W, Bagot C, Craven B, et al. Clinical features of vaccine-induced immune thrombocytopenia and thrombosis. N Engl J Med. 2021. https://doi.org/10.1056/ NEJMoa2109908.

30. Schulz JB, Berlit P, Diener H-C, Gerloff C, Greinacher A, Klein C, et al. COVID-19 vaccine-associated cerebral venous thrombosis in Germany. Ann Neurol. 2021. https://doi.org/10.1002/ ana.26172.

31. Schultz NH, Sørvoll IH, Michelsen AE, Munthe LA, LundJohansen F, Ahlen MT, et al. Thrombosis and thrombocytopenia after ChAdOx1 nCoV-19 vaccination. N Engl J Med. 2021;384:2124-30.

32. Makris M, Pavord S, Lester W, Scully M, Hunt B. Vaccineinduced immune thrombocytopenia and thrombosis (VITT). Res Pract Thromb Haemost. 2021;5:e12529.

33. Perry RJ, Tamborska A, Singh B, Craven B, Marigold R, ArthurFarraj $\mathrm{P}$, et al. Cerebral venous thrombosis after vaccination against COVID-19 in the UK: a multicentre cohort study. Lancet. 2021. https://doi.org/10.1016/S0140-6736(21)01608-1.

34. Warkentin TE, Greinacher A. Spontaneous HIT syndrome: knee replacement, infection, and parallels with vaccineinduced immune thrombotic thrombocytopenia. Thromb Res. 2021;204:40-51.

35. Scully M, Singh D, Lown R, Poles A, Solomon T, Levi M, et al. Pathologic antibodies to platelet factor 4 after ChAdOx $1 \mathrm{nCoV}$ 19 vaccination. N Engl J Med. 2021;384:2202-11.

36. Greinacher A, Thiele T, Warkentin TE, Weisser K, Kyrle PA, Eichinger S. Thrombotic thrombocytopenia after ChAdOx1 nCov-19 vaccination. N Engl J Med. 2021;384:2092-101.

37. Sánchez van Kammen M, Heldner MR, Brodard J, Scutelnic A, Silvis S, Schroeder V, et al. Frequency of thrombocytopenia and platelet factor $4 /$ heparin antibodies in patients with cerebral venous sinus thrombosis prior to the COVID-19 pandemic. JAMA. 2021;326:332-338.

38.• Huynh A, Kelton JG, Arnold DM, Daka M, Nazy I. Antibody epitopes in vaccine-induced immune thrombotic thrombocytopaenia. Nature. 2021;596:565-9. Discusses the difference in antibody targets for vaccine-induced thrombotic thrombocytopenia versus heparin-induced thrombocytopenia.

39. Bikdeli B, Chatterjee S, Arora S, Monreal M, Jimenez D, Krumholz HM, et al. Cerebral venous sinus thrombosis in the U.S. population, after adenovirus-based SARS-CoV-2 vaccination, and after COVID19. J Am Coll Cardiol. 2021;78:408-11.

40. Patriquin CJ, Laroche V, Selby R, Pendergrast J, Barth D, Côté B, et al. Therapeutic plasma exchange in vaccine-induced immune thrombotic thrombocytopenia. N Engl J Med. 2021;385:857-9.

41.• Rizk JG, Gupta A, Sardar P, Henry BM, Lewin JC, Lippi G, et al. Clinical characteristics and pharmacological management of COVID-19 vaccine-induced immune thrombotic thrombocytopenia with cerebral venous sinus thrombosis: a review. JAMA Cardiol. 2021. https://doi.org/10.1001/jamacardio.2021.3444. Overview of treatment of CVT associated with vaccineinduced thrombotic thrombocytopenia.

42. Idiculla PS, Gurala D, Palanisamy M, Vijayakumar R, Dhandapani S, Nagarajan E. Cerebral venous thrombosis: a comprehensive review. Eur Neurol. 2020;83:369-79.

43. Ferro JM, Canhão P, Stam J, Bousser M-G, Barinagarrementeria F, ISCVT Investigators. Prognosis of cerebral vein and dural sinus thrombosis: results of the International Study on Cerebral Vein and Dural Sinus Thrombosis (ISCVT). Stroke. 2004;35:664-70.

44. Duman T, Uluduz D, Midi I, Bektas H, Kablan Y, Goksel BK, et al. A multicenter study of 1144 patients with cerebral venous thrombosis: the VENOST Study. J Stroke Cerebrovasc Dis. 2017;26:1848-57.

45. Ferro JM, Canhão P, Bousser M-G, Stam J, Barinagarrementeria F, ISCVT Investigators. Cerebral vein and dural sinus thrombosis in elderly patients. Stroke. 2005;36:1927-32.

46. Lindgren E, Silvis SM, Hiltunen S, Heldner MR, Serrano F, de Scisco M, et al. Acute symptomatic seizures in cerebral venous thrombosis. Neurology. 2020;95:e1706-15.

47. Girot M, Ferro JM, Canhão P, Stam J, Bousser M-G, Barinagarrementeria $\mathrm{F}$, et al. Predictors of outcome in patients with cerebral venous thrombosis and intracerebral hemorrhage. Stroke. 2007;38:337-42.

48. Ortega-Gutierrez S, Holcombe A, Aksan N, Dai B, Shaban A, Lazarre L, et al. Association of admission clinical predictors and functional outcome in patients with cerebral venous and dural sinus thrombosis. Clin Neurol Neurosurg. 2020;188:105563.

49. Busch MA, Hoffmann O, Einhäupl KM, Masuhr F. Outcome of heparin-treated patients with acute cerebral venous sinus thrombosis: influence of the temporal pattern of intracerebral haemorrhage. Eur J Neurol. 2016;23:1387-92.

50. von Kummer R, Broderick JP, Campbell BCV, Demchuk A, Goyal M, Hill MD, et al. The Heidelberg Bleeding Classification: classification of bleeding events after ischemic stroke and reperfusion therapy. Stroke. 2015;46:2981-6.

51. Qureshi A, Perera A. Low molecular weight heparin versus unfractionated heparin in the management of cerebral venous thrombosis: a systematic review and meta-analysis. Ann Med Surg (Lond). 2017;17:22-6.

52.• Coutinho JM, Zuurbier SM, Bousser M-G, Ji X, Canhão P, Roos YB, et al. Effect of endovascular treatment with medical management vs standard care on severe cerebral venous thrombosis: the TO-ACT Randomized Clinical Trial. JAMA Neurol. 2020;77:966-73. Randomized clinical trial of endovascular therapy versus standard care in CVT.

53. Ferro JM, Crassard I, Coutinho JM, Canhão P, Barinagarrementeria F, Cucchiara B, et al. Decompressive surgery in cerebrovenous thrombosis. Stroke. 2011;42:2825-31.

54. Abstracts M. European Stroke Journal SAGE Publications. 2021;6:3-513.

55. Salottolo K, Bartt R, Frei DF, Bellon RJ, Atchie B, McCarthy K, et al. Timing of anticoagulation in patients with cerebral venous thrombosis requiring decompressive surgery: systematic review of the literature and case series. World Neurosurg. 2020;137:408-14. 
56. Field TS, Camden M-C, Al-Shimemeri S, Lui G, Lee AY. Offlabel use of novel anticoagulants for treatment of cerebral venous thrombosis: a Canadian survey. Int J Stroke. 2017;12:NP16-8.

57. Bose G, Graveline J, Yogendrakumar V, Shorr R, Fergusson DA, Le $\mathrm{Gal} \mathrm{G}$, et al. Direct oral anticoagulants in treatment of cerebral venous thrombosis: a systematic review. BMJ Open. 2021;11:e040212. Systematic review examining use of DOACs in CVT.

58. Oral rivaroxaban for the treatment of symptomatic pulmonary embolism. N Engl J Med. Massachusetts Medical Society; 2012;366:1287-1297.

59. Prins MH, Lensing AWA, Brighton TA, Lyons RM, Rehm J, Trajanovic M, et al. Oral rivaroxaban versus enoxaparin with vitamin $\mathrm{K}$ antagonist for the treatment of symptomatic venous thromboembolism in patients with cancer (EINSTEIN-DVT and EINSTEIN-PE): a pooled subgroup analysis of two randomised controlled trials. Lancet Haematol. 2014;1:e37-46.

60. Agnelli G, Buller HR, Cohen A, Curto M, Gallus AS, Johnson $\mathrm{M}$, et al. Apixaban for extended treatment of venous thromboembolism. N Engl J Med. 2013;368:699-708.

61. Schulman S, Kearon C, Kakkar AK, Mismetti P, Schellong $\mathrm{S}$, Eriksson $\mathrm{H}$, et al. Dabigatran versus warfarin in the treatment of acute venous thromboembolism. N Engl J Med. 2009;361:2342-52.

62. Ruff CT, Giugliano RP, Braunwald E, Hoffman EB, Deenadayalu N, Ezekowitz MD, et al. Comparison of the efficacy and safety of new oral anticoagulants with warfarin in patients with atrial fibrillation: a meta-analysis of randomised trials. Lancet. 2014;383:955-62.

63.• Ferro JM, Coutinho JM, Dentali F, Kobayashi A, Alasheev A, Canhão P, et al. Safety and efficacy of dabigatran etexilate vs dose-adjusted warfarin in patients with cerebral venous thrombosis: a randomized clinical trial. JAMA Neurol. 2019. https:// doi.org/10.1001/jamaneurol.2019.2764. Randomized clinical trial of dabigatran versus standard care in CVT.

64.• Connor P, Sánchez van Kammen M, Lensing AWA, Chalmers E, Kállay K, Hege K, et al. Safety and efficacy of rivaroxaban in pediatric cerebral venous thrombosis (EINSTEIN-Jr CVT). Blood Adv. 2020;4:6250-8. Substudy examining CVT cases in randomized clinical trial of rivaroxaban versus standard care in pediatric VTE.

65. Field TS, Dizonno V, Hill M. Ongoing clinical trials: study of rivaroxaban for CeREbral venous thrombosis (SECRET). Int $\mathbf{J}$ Stroke. 2019;14(3S). https://doi.org/10.1177/1747493019875933.

66. Pengo V, Denas G, Zoppellaro G, Jose SP, Hoxha A, Ruffatti A, et al. Rivaroxaban vs warfarin in high-risk patients with antiphospholipid syndrome. Blood. 2018;132:1365-71. Randomized clinical trial of rivaroxaban versus warfarin in highrisk APLAS.

67. Tektonidou MG, Andreoli L, Limper M, Amoura Z, Cervera R, Costedoat-Chalumeau $\mathrm{N}$, et al. EULAR recommendations for the management of antiphospholipid syndrome in adults. Ann Rheum Dis. 2019;78:1296-304.

68. Woller SC, Stevens SM, Kaplan DA, Rondina MT. Protocol modification of apixaban for the secondary prevention of thrombosis among patients with antiphospholipid syndrome study. Clin Appl Thromb Hemost. 2018;24:192.

69. Lancet T. Raising awareness of antiphospholipid antibody syndrome. Lancet. 2010;375:778.

70. Coutinho JM, Seelig R, Bousser M-G, Canhão P, Ferro JM, Stam $\mathrm{J}$. Treatment variations in cerebral venous thrombosis: an international survey. Cerebrovasc Dis. 2011;32:298-300.
71. Field TS, Camden M-C, Al-Shimemeri S, Lui G, Lee AYY. Antithrombotic strategy in cerebral venous thrombosis: differences between neurologist and hematologist respondents in a Canadian survey. Can J Neurol Sci. 2017;44:116-9.

72. Miranda B, Aaron S, Arauz A, Barinagarrementeria F, BorhaniHaghighi A, Carvalho M, et al. The benefit of EXtending oral antiCOAgulation treatment (EXCOA) after acute cerebral vein thrombosis (CVT): EXCOA-CVT cluster randomized trial protocol. Int J Stroke. 2018;13:771-4.

73.•• Aguiar de Sousa D, Lucas Neto L, Arauz A, Sousa AL, Gabriel D, Correia M, et al. Early recanalization in patients with cerebral venous thrombosis treated with anticoagulation. Stroke. 2020;51:1174-81. Prospective neuroimaging study examining early recanalization in CVT.

74. Ferro J, Bendszus M, Jansen O, Coutinho J, Dentali F, Kobayashi A, et al. Recanalization after cerebral venous thrombosis (CVT): a randomized controlled trial of the safety and efficacy of dabigatran etexilate versus dose-adjusted warfarin in patients with CVT. Int J Stroke. 2021. https://doi.org/10.1177/474930211006303.

75. de Sousa DA, Lucas Neto L, Canhão P, Ferro JM. Recanalization in cerebral venous thrombosis. Stroke. 2018;49:1828-35.

76. Ji K, Zhou C, Wu L, Li W, Jia M, Chu M, et al. Risk factors for severe residual headache in cerebral venous thrombosis. Stroke. 2021;52:531-6.

77. Palazzo Paola, Agius Pierre, Ingrand Pierre, Ciron Jonathan, Lamy Matthias, Berthomet Aline, et al. Venous thrombotic recurrence after cerebral venous thrombosis. Stroke. Am Heart Assoc. 2017;48:321-6. Systematic review and prospective study examining recurrence rates for CVT and risk factors.

78. Pires GS, Ribeiro DD, Oliveira JAQ, Freitas LC, Vaez R, Annichino-Bizzacchi JM, et al. Risk factors associated with recurrent venous thromboembolism after a first cerebral venous thrombosis event: a cohort study. Thromb Res. 2019;178:85-90. Prospective study examining recurrence rates in lower-risk individuals with CVT.

79.•• Sánchez van Kammen M, Lindgren E, Silvis SM, Hiltunen S, Heldner MR, Serrano F, et al. Late seizures in cerebral venous thrombosis. Neurology. 2020;95:e1716-23. Prospective study describing the natural history of seizures after CVT.

80. Ferro JM, Coutinho JM, Jansen O, Bendszus M, Dentali F, Kobayashi A, et al. Dural arteriovenous fistulae after cerebral venous thrombosis. Stroke. 2020;51:3344-7.

81. Eypasch E, Lefering R, Kum CK, Troidl H. Probability of adverse events that have not yet occurred: a statistical reminder. BMJ. 1995;311:619-20.

82. Preter M, Tzourio C, Ameri A, Bousser MG. Long-term prognosis in cerebral venous thrombosis. Follow-up of 77 patients. Stroke. 1996;27:243-6.

83. Schuchardt FF, Demerath T, Elsheikh S, Wehrum T, Harloff A, Urbach $\mathrm{H}$, et al. Dural arteriovenous fistula formation secondary to cerebral venous thrombosis: longitudinal magnetic resonance imaging assessment using 4D-combo-MR-venography. Thromb Haemost. 2021. https://doi.org/10.1055/s-0041-1723991.

Publisher's Note Springer Nature remains neutral with regard to jurisdictional claims in published maps and institutional affiliations. 